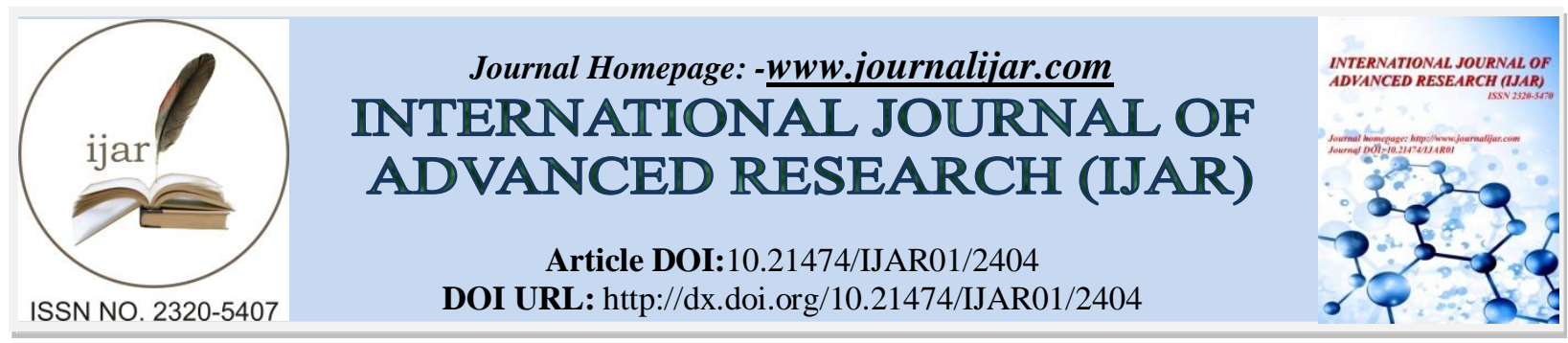

RESEARCH ARTICLE

VIRTUAL KEYBOARD.

\title{
23 RECURRENT MISCARRIAGE IN A WOMAN WITH SEPTATE UTERUS: CASE REPORT AND REVIEW OF THE LITERATURE.
}

\author{
Dania Mohammed Bresali ${ }^{1}$, Nawal Salim Alsenani ${ }^{1,2}$, Faisal Mansour Alsenani ${ }^{3}$ and WejdanYousef Basioni ${ }^{4}$. \\ 1. Faculty of Medicine, King Abdulaziz University, Jeddah, Saudi Arabia. \\ 2. MBBCh, MSc, Associated Professor, Department of Gynecology and Obstetric, King Abdulaziz University. \\ 3. Faculty of Medicine, IbnSina National College, Jeddah, Saudi Arabia. \\ 4. Faculty of Medicine, Battargi medical collage, Jeddah, Saudi Arabia.
}

\section{Manuscript Info}

Manuscript History

Received: 19 October 2016

Final Accepted: 20 November 2016

Published: December 2016

Key words:-

Recurrent miscarriage, septate uterus, hysteroscopy.

\section{Abstract}

Objective: To report a case of partial septate uterus with 23 consecutive recurrent miscarriages. As 23 recurrent miscarriages a rare condition.

$\operatorname{Method(s):~Case~report~and~review~of~the~literature,~in~obstetrics~and~}$ gynecology department at a tertiary care hospital. Case report of a 44 years old woman with 23 consecutive miscarriages.

Result(s): Initially hysterosalpingography suggested an arcuate uterus and a septate uterus, but magnetic resonance imaging review confirmed a partial septate uterus. The septum was repaired by operative hysteroscopy under laparoscopic guidance to attempt improvement of implantation as well as diminish her risk of recurrent miscarriages. The procedure was free of complication.

Conclusion(s): MRI is the optimal radiological study in diagnosis of uterine anomalies .

Further research aimed those women who failed to successful full term pregnancy has to be exposing to more intensive investigation before reach this high number of abortion.

Copy Right, IJAR, 2016,. All rights reserved.

\section{Introduction:-}

Recurrent miscarriage (RM) is defined as three or more consecutive abortion during first trimester[1]. The abnormal paternal karyotype, antiphospholipid antibody, endocrine disorders and uterine anomalies are the underlying causes responsible for first-trimester loss [2]. The most common uterine congenital anomalies are septate uterus [3], where the uterine cavity is separated by a longitudinal septum from the fundus to the cervix. The septum may involves only the superior part of the cavity or less frequently the total length of the uterine cavity and endocervical canal is separated into two components resulting in an incomplete septum or complete septum, respectively[4,5].

Female internal genital origins from fusion of the Mullerianducts, of which the middle part and tail develops into the uterus. During this fusion, a resorption process eliminates the partition to create a single cavity. A uterine septum is a result of abnormal resorption process of the septum between the paired Mullerianducts during early embryogenesis [5]. Uterine congenital anomalies particularly septate uteri are consider to be implicated in infertility and recurrent 
pregnancy loss $[6,7]$. It has been reported that patients with a septate uterus who underwent abdominal metroplasty could improve the subsequent reproductive outcomes. Hysteroscopicmetroplasty is considered as a common and less invasive way to treat septate uterus than other technique $[8,9]$.

In this case report, we reported a 44years old woman with 23 consecutive miscarriages. Following operative hysteroscopy under laparoscopic guidance was performed to attempt improvement in implantation as well as diminish her risk of RM.

\section{Case Report:-}

This report was completed after approval of Biomedical Ethics Unit. A 44-year-old woman presented to obstetrics and gynecology clinic at University Hospital following 23 consecutive miscarriage that most of it occurred between 8th -10th weeks of gestation (at first trimester) throughout 1986 and 2014. She had been married about 28 years and no infertility problem had been recorded. She had menarche at the age of 15 , and her menstrual cycle was regular, ranging from 24 or 25 days. Duration of bleeding ranged from 7 to 10 days, with normal flow, associated with primary dysmenorrhea before first pregnancy that was relieved by analgesia injection. The first 5 years of marriage she was on self planning, there is not history of oral contraceptives or IUD use. She was referred in 1991 for evaluation of 9 consecutive recurrent miscarriages; the first pregnancy was after 5 years of marriage and ended spontaneously at 16 week of gestation. Her mother has ten live children with a history of nine abortion and her sister has three abortion without a clear underlying cause. She had undergone D\&C for most of the abortion without complication or cervical incompetence.

Bimanual pelvic examination shows no abnormal findings. A complete screen of recurrent miscarriagewere performed[1]: coagulation profile, ANA profile, Lupus anticoagulant, AnticardiolipinIgG negative /IgM week positive, B2-glycoprotein-1 IgG/IgM, Protein C activity, Protein S activity (Fig.1), Cytogenetic analysis of both Partners, Endometrial biopsy, Thyroid-stimulating hormone and Prolactin, Fasting insulin and glucose, Factor V Leiden, Prothrombingene,MTHFR mutation, partial thromboplastin time (PTT) or activated partial thromboplastin time (aPTT), Antithrombin activity, Cervical/vaginal cultures were ruled out the abnormality. Ultrasound image shows a thickening in uterus (Fig.2,3). She had undergone hysterosalpingography, which initially revealed a deeply bifurcated uterine cavity that consistent with an arcuate uterus versus septate uterus (Fig.4), magnetic resonance imaging confirmed an existence of partial septate uterus (Fig. 5,6). Metroplasty was performed in 2015 based on numerous studies that report significant improvement in pregnancy outcome $[8,5,9]$. The septum was resected by operative hysteroscopy under laparoscopic guidance and had been sent to histopathology where was consistent with uterine septal tissue(Fig. 7). The laparoscopy showed a normal outer appearance of the uterus. She was discharged on the first postoperative day. The procedure was free of intra- or postoperative complications.

\section{Discussion And Review Of The Literature:-}

Recurrent miscarriage (RM) is defined as three or more consecutive pregnancy loss in first trimester [1]. The abnormal paternal karyotype, antiphospholipid antibody, endocrine disorders and uterine anomalies are the underlying causes responsible for first-trimester loss, respectively [2]. Although congenital uterine anomalies have a low rate of $5.5 \%$ in the population [10], the uterine malformation particularly septate uterus was strongly associated with infertility and recurrent pregnancy loss $[6,7,11]$. The incidence of Mullerian defects in women with a history of miscarriage is reported to be $13.3 \%$ but it is higher in women with infertility about $25 \%$ [10]. However, it has been reported that $68 \%$ of patients with a septate uterus who underwent abdominal metroplasty could have live baby births, including 102 cases with RM and 42 with primary infertility [8]. Removal of the septum improves the reproductive outcome, it can be done recently through hysteroscopicmetroplasty which is more effective and less invasive way to resect septate uterus than other technique [8, 9]. A review published in 2000 combined data from several published series; the spontaneous abortion was reported to be $88 \%$ but decrease to $14 \%$ after metroplasty. None of these studies were randomized; however, metroplasty in such cases has been accepted as the treatment of choice after two abortions when no other causes for the pregnancy losses are identified [5]

This report represents a case of attempted management of septate uterus in 23 consecutive spontaneous abortions with hysteroscopicmetroplasty. That was diagnosed by pelvic MRI without contrast. However, the question is raised whether women of 44 years old with a septate uterus and metroplasty could be preceded to a successful pregnancy and healthy baby. 
A case report described that successful pregnancy in a woman with 12 previous pregnancies loses after second metroplasty; however, it indicated that is due to uterine septum [12]. Das, H., et al. reported a woman who had five consecutive abortions with underlying cause of septate uterus, ended in a term pregnancy following modified Jones' metroplasty operation [13]. [3] Reported also a 29 year old nulliparous woman with a successful pregnancy outcome following Tompkins metroplasty done early.

Others reported a woman with 19 recurrent miscarriages but this was due to underlying cause of massive uterine NK cells, ended in a term pregnancy after preconceptual prednisone treatment[14].

There is not a report of a high number of RM, i.e., 23RM in a woman with underlying cause of septate uterus.

Other studies are reported with a history of recurrent miscarriage that associated with underlying uterine septum and other causes showed in table 1 .

We conclude that the MRI is the optimal radiological study in diagnosis of uterine anomalies. Further research aimed those women who failed to successful full term pregnancy has to be exposing to more intensive investigation before reach this high number of abortion.

\section{Consent}

Written informed consent was acquired from the patient or publication of this case report and accompanying images.

Table1:- Case reports are associated with a history of recurrent miscarriageand pregnancy out come poster

\begin{tabular}{|c|c|c|c|c|}
\hline Study & $\begin{array}{l}\text { No. of pregnancy } \\
\text { loss }\end{array}$ & $\begin{array}{l}\text { Subject } \\
\text { causes }\end{array}$ & Management & $\begin{array}{l}\text { Sucsseful } \\
\text { pregnancy }\end{array}$ \\
\hline Simons et al, 2011 & 4 & $\begin{array}{l}\text { Large uterine septum } \\
\text { and bicornuateuterus. }\end{array}$ & Hysteroscopicmetroplasty & - \\
\hline Choe JK et al , 2009 & 6 & Uterine septum & Hysteroscopicmetroplasty & $\sqrt{ }$ \\
\hline DaCosta, 2002 & 3 & Uterine septum & Hysteroscopicmetroplasty & $\sqrt{ }$ \\
\hline Quenby et al, 2003 & 19 & $\begin{array}{l}\text { Massive uterine NK } \\
\text { cell }\end{array}$ & $\begin{array}{l}\text { preconceptual } \\
\text { prednisolone }\end{array}$ & $\sqrt{ }$ \\
\hline $\begin{array}{l}\text { Ogasawara M,et al, } \\
2000\end{array}$ & 10 & $\begin{array}{l}\text { Massive uterine NK } \\
\text { cell }\end{array}$ & Uterine Steroid Therapy & $\sqrt{ }$ \\
\hline Das et al, 1997 & 5 & Uterine septum & $\begin{array}{l}\text { modified Jones' metroplasty } \\
\text { operation }\end{array}$ & $\sqrt{ }$ \\
\hline Quereet al, 1998 & 5 & hyperhomocysteinemia & $\begin{array}{l}\text { folic acid, } \\
15 \mathrm{mg} \text { daily, and vitamin } \mathrm{B} 6 \text {, } \\
500 \mathrm{mg} \text { daily. }\end{array}$ & $\sqrt{ }$ \\
\hline $\begin{array}{l}\text { Abu-Musa et al, } \\
1998\end{array}$ & 7 & Partial uterine septum & $\begin{array}{l}\text { Tompkins } \\
\text { metroplasty }\end{array}$ & $\sqrt{ }$ \\
\hline $\begin{array}{l}\text { Heinonen PK et al, } \\
1986\end{array}$ & 12 & Uterine septum & $\begin{array}{l}\text { A second metroplasty was } \\
\text { performed } 12.5 \text { years after the } \\
\text { first, and after two } \\
\text { miscarriageshe conceived }\end{array}$ & $\sqrt{ }$ \\
\hline
\end{tabular}


Figure1:- The lapratory investigation of patient is within normal rages.

\begin{tabular}{|c|c|c|c|c|}
\hline Test Name & Result & Unit & & Reference Range \\
\hline Anticardiolipin Antibody-G (ACA-G) & $<0.5$ & $\mathrm{U} / \mathrm{mL}$ & 0 & -10 \\
\hline Anticardiolipin Antibody-M (ACA-M) & $\begin{array}{l}18 ; \text { Weak Positive (Reference Range }=0 \text { - } \\
\text { 10) }\end{array}$ & $\mathrm{U} / \mathrm{mL}$ & 0 & .7 \\
\hline B2 Glycoprotein IgM & 2.7 & $\mathrm{U} / \mathrm{ml}$ & & - \\
\hline B2-Glycoprotein-IgG & $<0.6$ & $\mathrm{U} / \mathrm{mL}$ & & . \\
\hline
\end{tabular}

\section{End of Report}

$\frac{\text { Test Name }}{\text { APC Resistance ( functional factor } V \text { liden) }}$

Result

Protein S Activity

Protein C Activity

Factor VIII assay

Antithrombin III Activity

Lupus Anticogulant 1
H 1.18

90.9

126.2

140.7

88.3

29.9

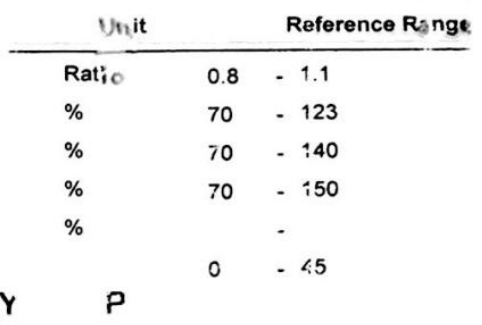

rY

. 
Figure 5,6:- MRI showing a thin partial septum. Diagnosis of a partial uterine septum was assumed based on the history and this imaging.
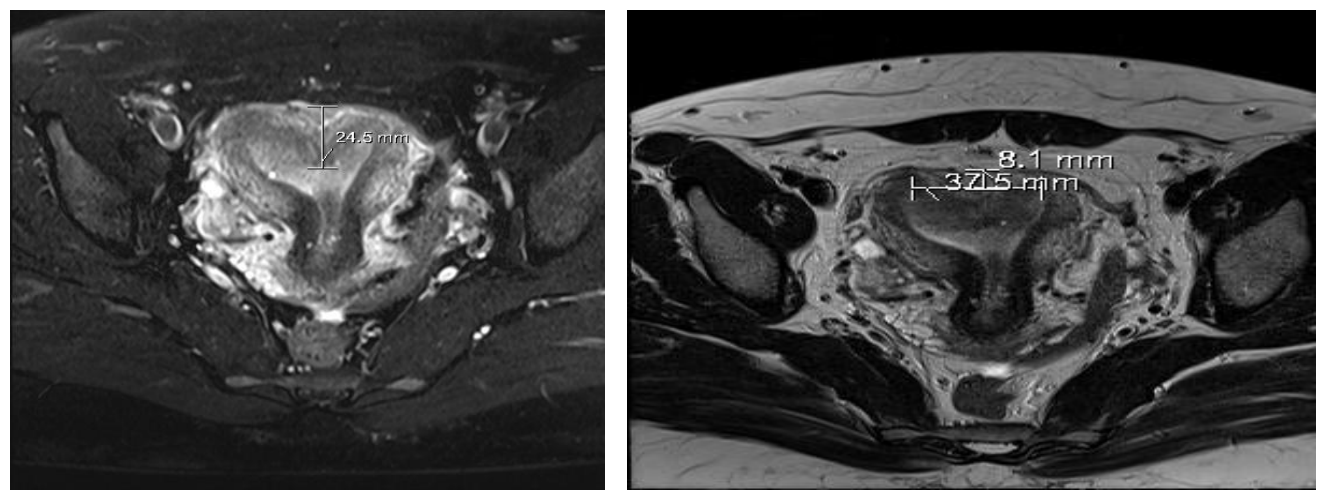

Figure 7:-The septum was resected by hysteroscopy under laparoscopic guidance.

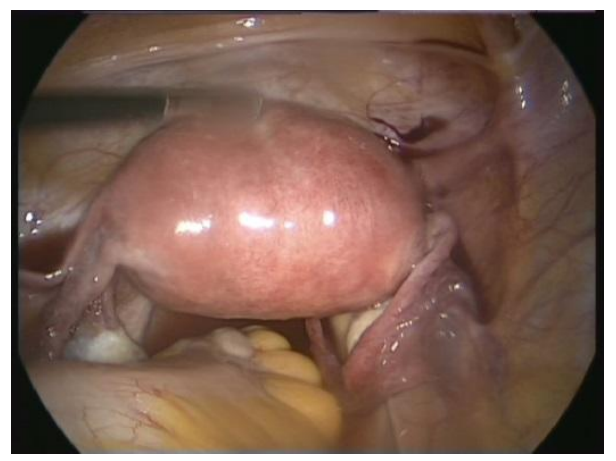

\section{References:-}

1. Stephenson, Mary, and William Kutteh. "Evaluation and management of recurrent early pregnancy loss." Clinical obstetrics and gynecology 50.1 (2007): 132-145.

2. Li, T. C. "Guides for practitioners Recurrent miscarriage: principles of management." Human Reproduction 13.2 (1998): 478-482.

3. Abu-Musa, A., et al., Successful pregnancy outcome following Tompkins metroplasty done early in pregnancy. Human Reproduction, 1998. 13(5): p. 1387-1388.

4. Guo, Xiaoqiao, et al. "Successful pregnancy in each half uterus cavity of the septate uterus after transferring three embryos in one half-cavity: a case report." Journal of ovarian research 6.1 (2013): 1.

5. Pabuçcu, Recai, and Victor Gomel. "Reproductive outcome after hysteroscopicmetroplasty in women with septate uterus and otherwise unexplained infertility."Fertility and sterility 81.6 (2004): 1675-1678.

6. Sugiura-Ogasawara, Mayumi, Yasuhiko Ozaki, and NobuhiroSuzumori. "Müllerian anomalies and recurrent miscarriage." Current Opinion in Obstetrics and Gynecology 25.4 (2013): 293-298.

7. Jaslow, Carolyn R., and William H. Kutteh. "Effect of prior birth and miscarriage frequency on the prevalence of acquired and congenital uterine anomalies in women with recurrent miscarriage: a cross-sectional study." Fertility and sterility 99.7 (2013): 1916-1922.

8. CANDIANI, G.B., et al., Reproductive prognosis after abdominal metroplasty in bicornuate or septate uterus: a life table analysis. BJOG: An International Journal of Obstetrics \&Gynaecology, 1990. 97(7): p. 613-617.

9. Homer, H.A., T.-C. Li, and I.D. Cooke, The septate uterus: a review of management and reproductive outcome. Fertility and sterility, 2000. 73(1): p. 1-14.

10. Chan, Y., et al., The prevalence of congenital uterine anomalies in unselected and high-risk populations: a systematic review. Human reproduction update, 2011: p. dmr028.

11. Saravelos, Sotirios H., Karen A. Cocksedge, and Tin-Chiu Li. "The pattern of pregnancy loss in women with congenital uterine anomalies and recurrent miscarriage." Reproductive biomedicine online 20.3 (2010): 416422 . 
12. Heinonen, Pentti K., AnttiSavolainen, and PaavoPystynen. "Septate uterus and habitual abortion: a case report illustrating successful outcome of pregnancy after second metroplasty." European Journal of Obstetrics \& Gynecology and Reproductive Biology 23.3 (1986): 233-238.

13. Das, H., et al. "Consecutive five abortions in a case of septate uterus--ended in a term pregnancy following modified Jones' metroplasty operation." Journal of the Indian Medical Association 95.1 (1997): 23.

14. Quenby, Siobhan, et al. "Successful pregnancy outcome following 19 consecutive miscarriages: case report." Human Reproduction 18.12 (2003): 2562-2564. uterine septum." Fertility and sterility 96.2 (2011): e118-e121.

15. Simons, et al. Hysteroscopicmorcellator system can be used for removal of a uterine septum. Fertility and sterility 96.2 (2011): e118-e121.

16. Choe JK, Check JH, Chern R, Septoplasty allows successful delivery in a primary aborter with six previous first trimester miscarriages. ClinExpObstet Gynecol. 2009;36(1):15-6.

17. Dacosta, V., et al., Successful pregnancy after hysteroscopicmetroplasty. The West Indian medical journal, 2002. 51(4): p. 260-262.

18. OGASAWARA, MAYUMI, and KOJI AOKI. "Successful uterine steroid therapy in a case with a history of ten miscarriages." American Journal of Reproductive Immunology 44.4 (2000): 253-255.

19. Quere, Isabelle, et al. "A woman with five consecutive fetal deaths: case report and retrospective analysis of hyperhomocysteinemia prevalence in 100 consecutive women with recurrent miscarriages." Fertility and sterility 69.1 (1998): 152-154. 